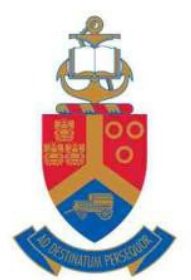

UNIVERSITEIT VAN PRETORIA UNIVERSITY OF PRETORIA YUNIBESITHI YA PRETORIA
Faculty of Engineering, Built Environment and Information Technology

Department of Mining Engineering

\section{Postgraduate Brochure}

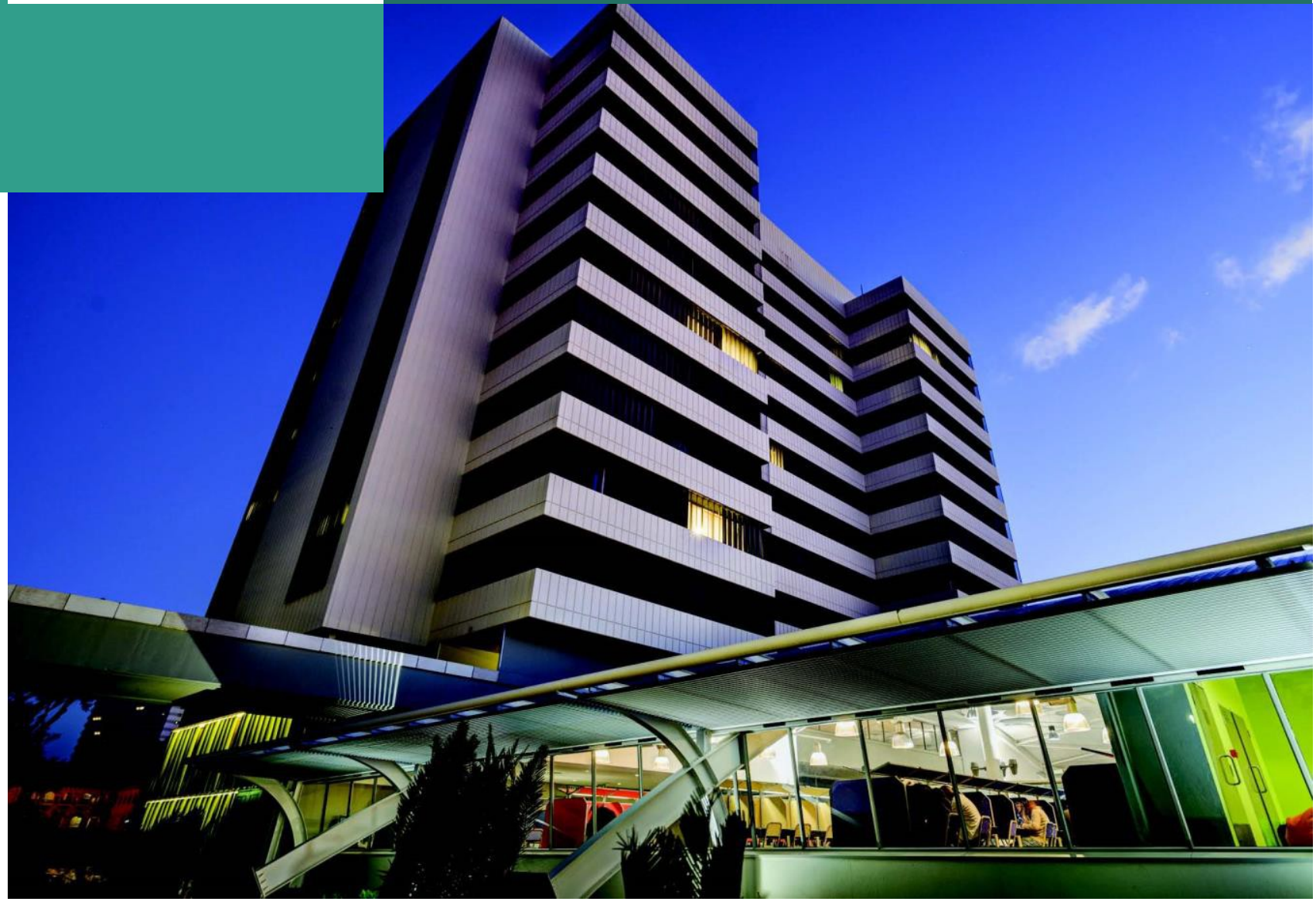




\section{Contents}

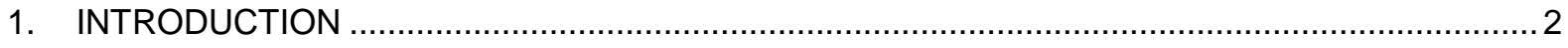

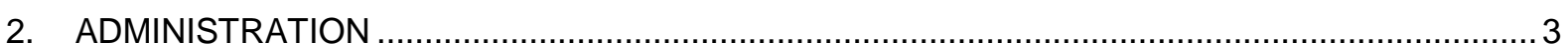

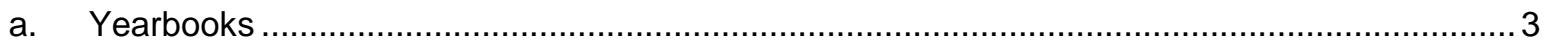

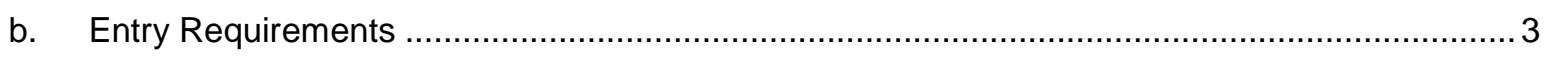

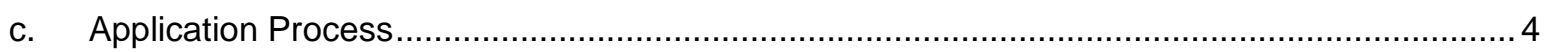

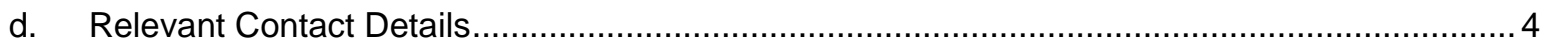

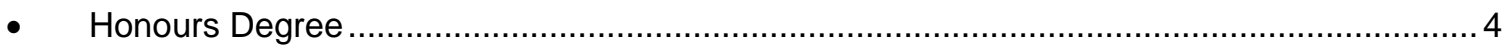

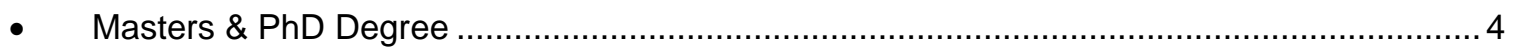

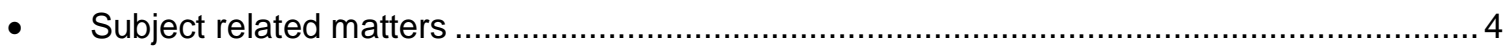

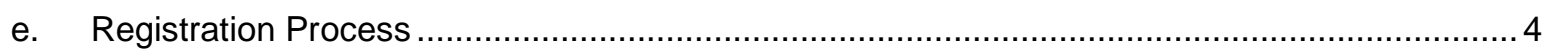

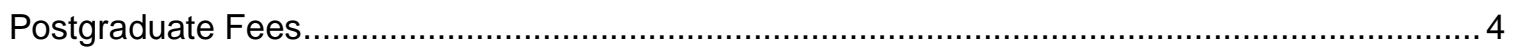

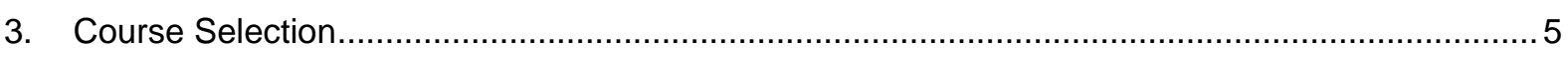

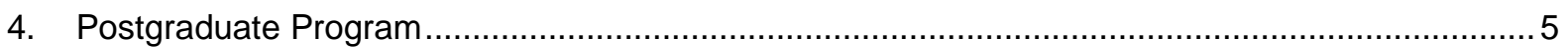

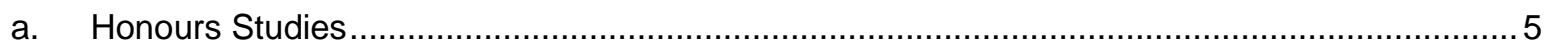

BEng(Hons)(Mining Engineering)(12240072) (64 credits) ...................................................... 5

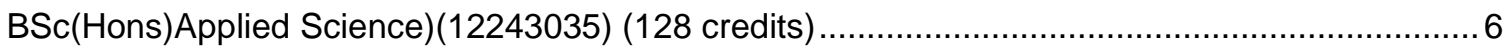

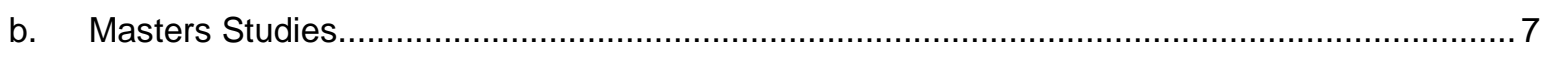

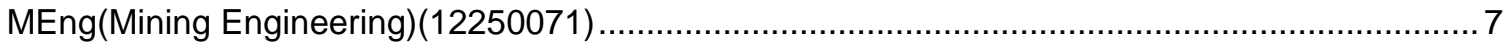

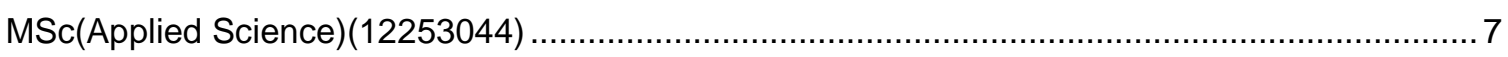

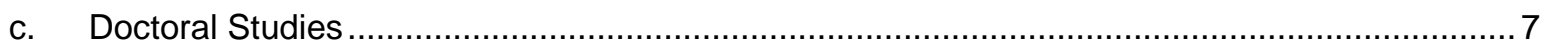

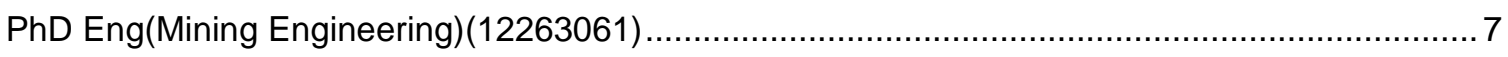

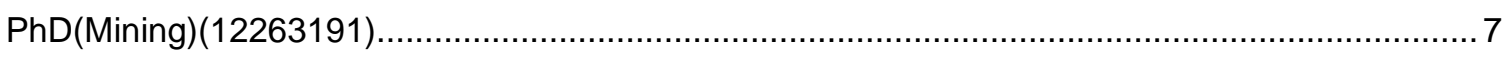




\section{INTRODUCTION}

The postgraduate degree programs in the Department are open to graduates holding a recognised degree in either engineering (BEng), science (BSc) or technology (BTech). The courses are intended for graduates who wish to enhance their skills in Mining Engineering, or for other professionals who wish to further their academic qualifications in aspects of Mining Engineering.

The courses offer subjects in a broad spectrum, covering introductory aspects of mining engineering, through to consolidation, skills enhancement and mining research-related projects, dissertations and theses. A number of courses may be taken from other engineering disciplines where the student requires specialist knowledge not available in the Mining program (subject to Department Head approval). Students should refer to the appropriate Departmental brochure for further details of these courses.
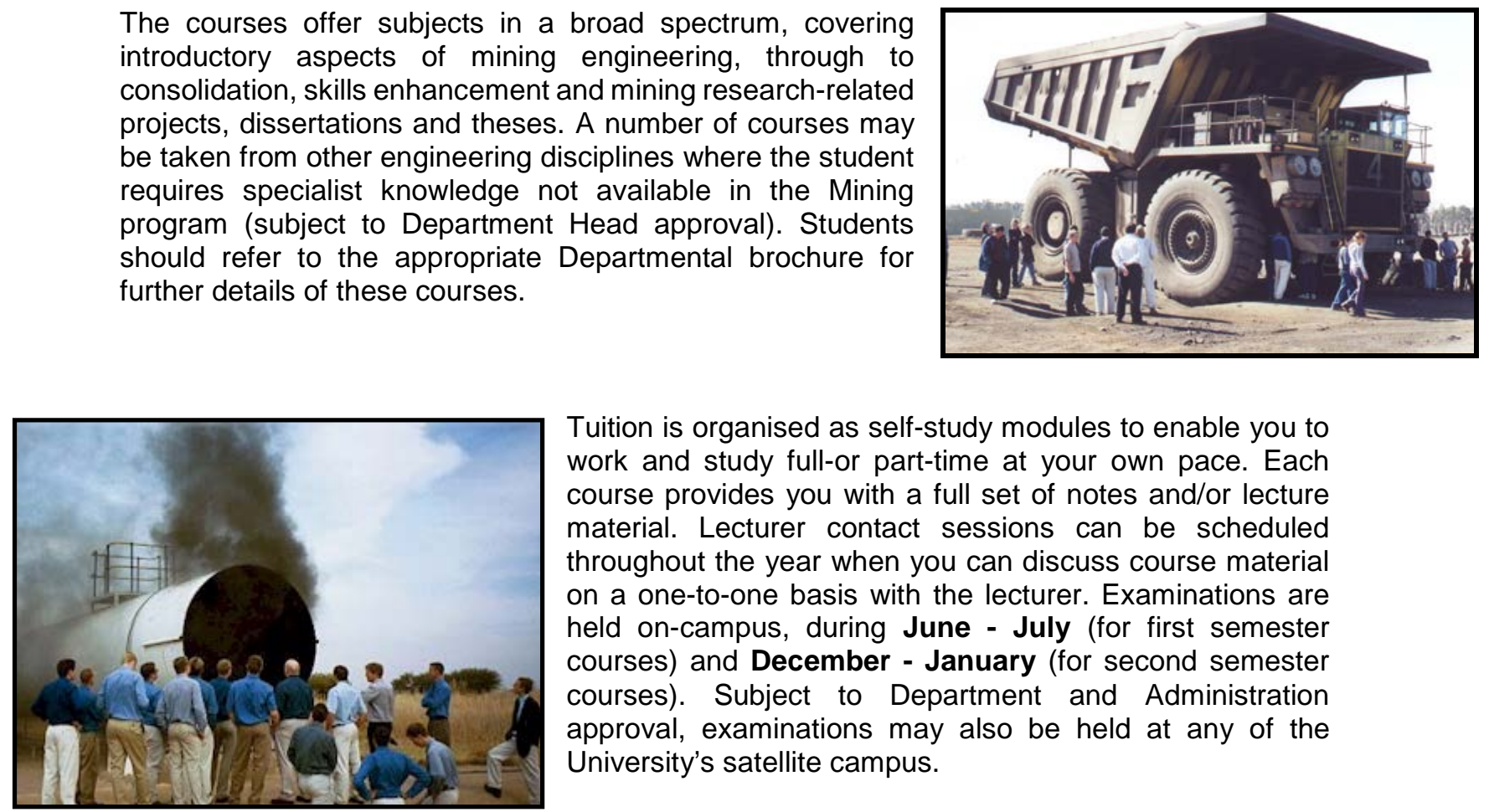

Tuition is organised as self-study modules to enable you to work and study full-or part-time at your own pace. Each course provides you with a full set of notes and/or lecture material. Lecturer contact sessions can be scheduled throughout the year when you can discuss course material on a one-to-one basis with the lecturer. Examinations are held on-campus, during June - July (for first semester courses) and December - January (for second semester courses). Subject to Department and Administration approval, examinations may also be held at any of the University's satellite campus.

A number of our modules will in the near future be in digital format, which provides you with greater flexibility in your learning. We are in the process of expanding the use of web- and CDbased education for your benefit and to stay at the cutting edge of education innovation. Thus, we hope to accommodate your work schedule with a flexible study program.

With all these study opportunities to increase your knowledge and skills in contributing to the growth of our industry, country and continent I look forward to welcoming you to the program.

\section{Prof Ronny Welter-Youngman}

Head: Department of Mining Engineering 


\section{ADMINISTRATION}

\section{a. Yearbooks}

This information brochure should be read in conjunction with the following Yearbook of the (EBIT Faculty) University of Pretoria. Please follow the website link mentioned herewith: http://www.up.ac.za/yearbooks/home

\section{b. Entry Requirements}

Welcome to the postgraduate programme in the Department of Mining Engineering at the University of Pretoria. This brochure contains relevant information on the postgraduate courses offered on a full- and part-time basis.

The following postgraduate degrees are awarded in the School of Engineering (minimum/maximum duration in brackets):

Honours degrees: (minimum duration: one year / maximum three years)

- Bachelor of Engineering (Honours) - BEng(Hons) - for students who have obtained an accredited University engineering degree or equivalent. (see programme information)

- Bachelor of Science (Honours) - BSc(Hons) Applied Science - for students who have obtained a relevant 3-year University degree, non-accredited engineering degree or a BTech degree. (see programme information)

Master's degrees: (minimum duration: one year / maximum two years)

- Master of Engineering - MEng - for students who have obtained a BEng (Hons) University degree or equivalent (see programme information)

- Master of Science - MSc Applied Science - for students who have obtained a BSc (Hons)(Applied Science) degree (see programme information)

Doctorates: (minimum duration: one year / maximum three years)

- Doctor of Philosophy- PhD - for students who have obtained a relevant Master's degree (see programme information)

- Doctor of Philosophy in Engineering - $\mathrm{PhD}(\mathrm{Eng})$ - for persons who have obtained a relevant Master's degree in engineering (see programme information)

Irrespective of any comments contained in this brochure, the following will apply:

- General Regulations, Rules \& Glossary of Terms;

- Faculty of Engineering, Built Environment and Information Technology Yearbook

Note that the academic status of degrees obtained at other universities, especially graduates from overseas Universities, need to be clarified with the Student Administration Offices. Refer also to the Regulations G.29-G.38 part 1, of the relevant year(s) of registration.

Although every attempt was made to ensure that this brochure is correct and up to date at the time of publishing, the Department reserves the right to make any changes without prior notice and without prejudice. 


\section{c. Application Process}

If you are applying at the University of Pretoria for postgraduate studies, please submit a completed online application form before 31 October of each year for studies that commence the following year. Click here to apply on-line.

Once your application has been submitted, you may however contact the Student Service Centre in writing at ssc@up.ac.za if you wish to add any additional information, or make any changes to your application.

Please note that application fees may apply. Click here for the Postgraduate fee structure

Note: All applications are approved by the Head of Department. Student Administration will be able to provide you proof of registration on condition that all financial obligations are met i.e. all outstanding course and registration fees are paid.

\section{d. Relevant Contact Details}

\section{- Honours Degree}

Enquiries:

Mr Joseph Makhasa

joseph.makhasa@up.ac.za

\section{Applications:}

Me Sibongile Mgiba

laurrine.mgiba@up.ac.za

- Masters \& PhD Degree

Enquiries \& Applications:

Me Stefanie Steenberg

stefanie.steenberg@up.ac.za

\section{- Subject related matters}

Me Marietha Hicks mining.postgrad@up.ac.za

\section{e. Registration Process}

The student's registration must be renewed annually until such time as the degree requirements have been complied with. Candidates who fail to renew their registration or who interrupt their studies are liable for the full tuition fees when the study is recommenced.

\section{Postgraduate Fees}

Refer to the Postgraduate Fees, which gives details regarding tuition fees and payments. 


\section{Course Selection}

The following modules are offered in the various programs. Note that the listing of a module on the approved application form does not constitute a guarantee that the module will be offered. Students should note that even if a module is listed, only those modules for which there is sufficient demand will be offered each year. Students must also confirm during registration that the modules are being offered and in which semester. NO semester changes will be accommodated.

Should a student decide during the academic year to discontinue any modules for which he/she enrolled, a form should be obtained from Student Administration (dawn.taljaard@up.ac.za), completed and submitted. Please NOTE that late cancellations will result in payment of full fees. Refer to University Calendar for details of latest date to cancel without penalties (http://www.up.ac.za/calendars).

To discontinue studies, a student should refer to the Student Service Centre (ssc@up.ac.za). Should a student wish to change module(s) after registration, he/she must complete the official "Change of Subject/Module" form (dawn.taljaard@up.ac.za) and submit to Head of Department for approval. The closing dates for these changes are also shown in the University Calendar.

All changes of student details must be communicated to the Head of Department AND updated using the Students on-line system.

\section{Postgraduate Program}

\section{a. Honours Studies}

Each module offered at Honours level is assigned a number of SAQA credits. Approximately 10 hours of study are required per SAQA credit. A total of 128 SAQA credits need to be obtained to complete the Honours degree. The modules described later in detail are either 16 or 32 SAQA credits per module.

All subjects lean towards distance learning and compulsory contact sessions could be scheduled if and where necessary per module. These sessions will be communicated timeously.

\section{BEng(Hons)(Mining Engineering)(12240072) (64 credits)}

A minimum of 32 credits should be accumulated per year and the programme should be completed within two years. A limited number of appropriate modules from other departments are allowed. Refer to individual Departments post-graduate brochures. 
Please click here for all module descriptions for below modules

\begin{tabular}{|l|l|l|}
\hline Year Module & Code & Credits \\
\hline Research Project 700 & PSS 700 & $32[\mathrm{C}]$ \\
\hline Semester 1 Module & & \\
\hline Financial Mine Valuation & PFZ 780 & $16[E]$ \\
\hline Heat \& Refrigeration & PKB 712 & $16[E]$ \\
\hline Semester 2 Module & & \\
\hline Advanced Design: Mining & PMZ 780 & $16[E]$ \\
\hline Slope Stability & PHS 781 & $16[E]$ \\
\hline Airflow \& Fans & PKB 711 & $16[E]$ \\
\hline Strata Control & PSZ 786 & $16[E]$ \\
\hline Surface Mining & POY 783 & $16[E]$ \\
\hline Advanced Explosives Engineering & PRX 785 & $16[E]$ \\
\hline \multicolumn{1}{|c|}{ [C]: Modules are Core / Compulsory } & & \\
\hline
\end{tabular}

BSc(Hons)Applied Science)(12243035) (128 credits)

A minimum of 32 credits should be accumulated per year and the programme should be completed within two years.

\begin{tabular}{|l|l|l|}
\hline Year Module & Code & Credits \\
\hline Research Project 700 & PSS 700 & $32[\mathrm{C}]$ \\
\hline Semester 1 Module & & \\
\hline Underground Mining Methods & PMY 701 & $32[\mathrm{C}]$ \\
\hline Surface Mining & PMY 703 & $16[\mathrm{C}]$ \\
\hline Basic Rock Mechanics & PSZ 703 & $16[\mathrm{C}]$ \\
\hline Semester 2 Module & & \\
\hline Basic Mine Ventilation Engineering & PKB 701 & $16[\mathrm{C}]$ \\
\hline Explosive Engineering & PRX 701 & $16[\mathrm{C}]$ \\
\hline
\end{tabular}

[C]: All Modules are Core / Compulsory

PMY 703 Basic Mining Methods is a pre-requisite for the second semester modules. Failing the module will result in exclusion from the rest of the programme 
b. Masters Studies

Please click here for all module descriptions for below modules

MEng(Mining Engineering)(12250071)

\begin{tabular}{|l|l|l|}
\hline Module & Code & Credits \\
\hline Dissertation 890 & PYI 890 & 128 \\
\hline
\end{tabular}

MSc(Applied Science)(12253044)

\begin{tabular}{|l|l|l|}
\hline Module & Code & Credits \\
\hline Dissertation 891 & PYI 891 & 128 \\
\hline
\end{tabular}

c. Doctoral Studies

PhD Eng(Mining Engineering)(12263061)

\begin{tabular}{|l|l|l|}
\hline Module & Code & Credits \\
\hline Thesis 990 & MYI 990 & 360 \\
\hline
\end{tabular}

PhD(Mining)(12263191)

\begin{tabular}{|l|l|l|}
\hline Module & Code & Credits \\
\hline Thesis 990 & MYL 990 & 360 \\
\hline
\end{tabular}

